\title{
Regenerative energy management of electric drive based on Lyapunov stability theorem
}

\author{
Shahab SABZI ${ }^{1}$, Mehdi ASADI ${ }^{1}$, Hassan MOGHBELI ${ }^{1}$
}

\begin{abstract}
In recent years, urban rail systems have developed drastically. In these systems, when induction electrical machine suddenly brakes, a great package of energy is produced. This package of energy can be stored in energy storage devices such as battery, ultra-capacitor and flywheel. In this paper, an electrical topology is proposed to absorb regenerative braking energy and to store it in ultracapacitor and battery. Ultra-capacitor can to deliver the stored energy to DC grid and to charge the battery for auxiliary applications such as lighting and cooling systems. The proposed system is modeled based on large signal averaged modeling, which leads to the simplicity of calculations. The control system is based on Lyapunov stability theorem which guarantees system stability. Also, an energy management algorithm is proposed to control energy under braking and steady-state conditions. Finally, the simulation results validate the effectiveness of the proposed control and energy management system.
\end{abstract}

Keywords DC/DC converter, Lyapunov stability, Bidirectional converter, Energy management system (EMS), Ultra-capacitor, Battery, Switching function

CrossCheck date: 27 November 2018

Received: 10 March 2018/ Accepted: 27 November 2018/Published online: 18 January 2019

(C) The Author(s) 2019

Mehdi ASADI

m.asadi@arakut.ac.ir

Shahab SABZI

Shahab.sabzi@gmail.com

Hassan MOGHBELI

hamoghbeli@yahoo.com

1 Department of Electrical Engineering, Arak University of Technology, Arak, Iran

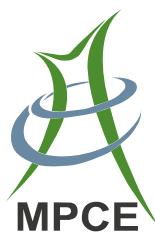

\section{Introduction}

Capacity, reliability and safety of urban rail systems make these devices suitable for public transportation in developed countries [1,2]. Considering energy price and climate change, energy saving has become an important subject for research studies. Consumed energy in urban rail systems is divided into two parts, traction usage and nontraction usage. In such systems, about $50 \%$ of total consumed energy is related to the traction requirements and the rest is related to non-traction usage or auxiliary systems, such as cooling systems and lighting systems [3, 4], and therefore designing a power electronic topology capable of providing energy for these usages, apart from many benefits, can be useful to the economy.

The topic of energy saving in urban rail systems has been investigated in different aspects. In [5], an energy management strategy for capacitor is proposed to adjust charging and discharging threshold voltage based on analysis of train operation states. The main parameter for energy calculations is state of charge (SOC) of energy storage device. In [6], capacitor is used for energy saving in train systems and a hierarchical control strategy is proposed based on energy management section and converter control section. The energy management system works based on an introduced machine and converter control mainly consist of a proportional-integral (PI) closed-loop strategy. Also an optimization algorithm is proposed to estimate the control parameter values at different operations. In [7], a train system considering renewable energy sources (photovoltage and wind power) and the capabilities of using regenerative braking energy is investigated. Apart from these aspects, uncertainties of renewable energies are considered through different scenarios and the whole problem is considered and solved as a large-scale nonlinear 
optimization problem. Energy and economic energy saving of the proposed system under different strategies is also studied.

In this paper, a topology for saving regenerative braking energy in storage devices is proposed and control system is designed. A bidirectional DC/DC converter and a unidirectional DC/DC converter are connected in series. Also, ultra-capacitor and battery are used as main energy storage devices. Regenerative energy generated by induction electrical machine (IEM) is a high power density package of energy which occurs during a very short period of time, so must be stored in a device with high power density such as ultra-capacitor [8-10]. To increase the reliability and system efficiency, ultra-capacitor is connected to DC link via a bidirectional DC/DC converter [11-14].

To control the proposed system, switching functions are extracted based on state-space equations [15]. Extraction of switching functions is a well-known method to control switching process of power electronic devices, in which, switching functions are obtained based on system's requirements [16]. In this paper, switching functions are extracted using fundamentals of Lyapunov stability theorem. Fast and accurate tracking of reference values and maintaining system's stability are main advantages of this method.

\section{Modeling and control of proposed system}

Schematic circuit diagram of the system is shown in Fig. 1a and power electronic model of the system is shown in Fig. 1b. As seen, the converter that is connected to the DC link and ultra-capacitor is bidirectional and the converter between ultra-capacitor and battery is unidirectional. $I_{m}$ is the current from IEM to DC link capacitor. $I_{L_{1}}$ is the current of bidirectional converter and is positive if the converter works in buck mode, or negative if the converter works in boost mode. $I_{L_{2}}$ that is either positive or zero, is the current of buck converter. $V_{d c}$ and $C_{d c}$ are the voltage and capacitor of DC link, respectively. Also, $C_{u c}, R_{u c}$ and $V_{u c}$ are capacity, resistance and voltage of ultra-capacitor, respectively. $V_{b}$ is voltage of the battery. $d_{1}, d_{2}, d_{3}$ are the duty cycles of switches $\mathrm{S} 1, \mathrm{~S} 2$ and $\mathrm{S} 3$, respectively. $L_{1}$ and $L_{2}$ are the inductors of bidirectional and unidirectional converters, respectively. Moreover, there is a dynamic resistor $R_{\text {dynamic }}$ that must dissipate surplus energy when DC link capacitor and ultra-capacitor are fully charged. Therefore, $S_{\mathrm{d}}$ and $u_{\mathrm{d}}$ are the switch and its duty cycle of the circuit that connect the dynamic resistor to the DC link.

A well-known method to model switching circuits is large signal averaged model, leading to simplicity of

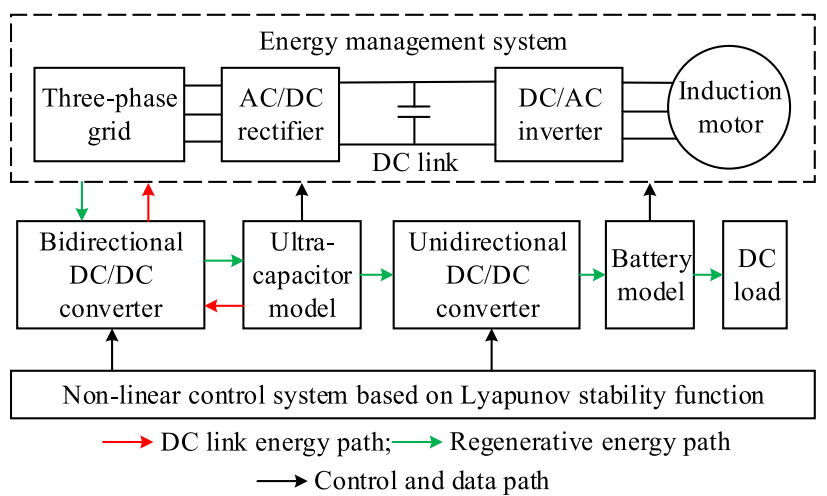

(a) Schematic circuit diagram

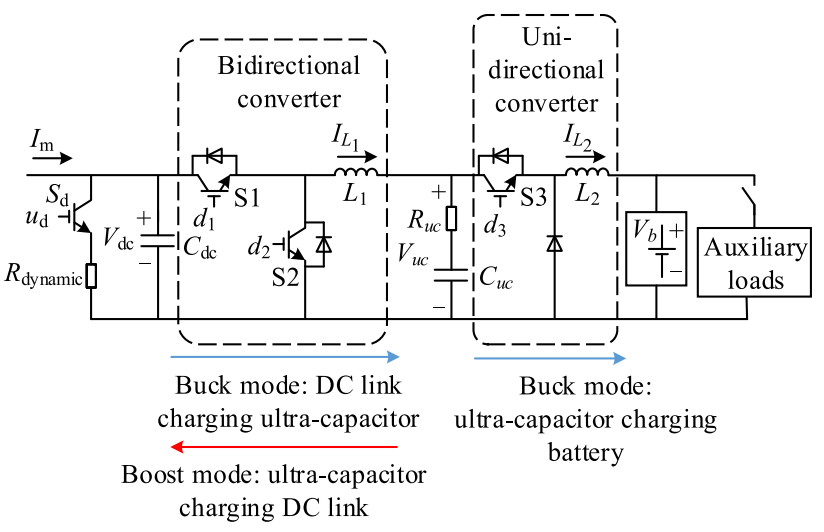

(b) Power electronic model

Fig. 1 Complete proposed system for absorbing regenerative braking energy in battery and ultra-capacitor

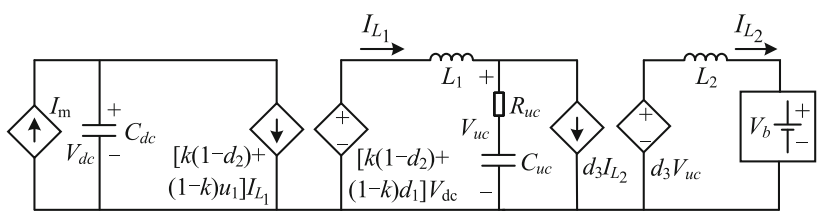

Fig. 2 Large signal averaged model of proposed system

systems [17]. Averaged model of proposed system is shown in Fig. 2, where $k$ is described as:

$k= \begin{cases}1 & I_{L_{1}}<0 \text { (boost) } \\ 0 & I_{L_{1}}>0 \text { (buck) }\end{cases}$

Converters are controlled using switching functions, based on Lyapunov stability theorem. Switching functions are obtained separately for every state. In order to express the equations, first a new term named $d_{12}$ combined of $d_{1}$ and $d_{2}$ is generated as [18]:

$d_{12}=k\left(1-d_{2}\right)+(1-k) d_{1}$

where $d_{12}$ is the switching function of bidirectional converter. 


\subsection{Switching functions extraction using Lyapunov stability theorem}

Equation (3) indicates the state-space matrix of the averaged model of Fig. 2.

$$
\left[\begin{array}{l}
\dot{I}_{L_{1}} \\
\dot{I}_{L_{2}} \\
\dot{V}_{d c} \\
\dot{V}_{u c}
\end{array}\right]=\left[\begin{array}{cccc}
\frac{-R_{u c}}{L_{1}} & \frac{d_{3} R_{u c}}{L_{1}} & \frac{d_{12}}{L_{1}} & \frac{-1}{L_{1}} \\
0 & 0 & 0 & \frac{d_{3}}{L_{2}} \\
\frac{-d_{12}}{C_{d c}} & 0 & 0 & 0 \\
\frac{1}{C_{u c}} & \frac{-d_{3}}{C_{u c}} & 0 & 0
\end{array}\right]\left[\begin{array}{l}
I_{L_{1}} \\
I_{L_{2}} \\
V_{d c} \\
V_{u c}
\end{array}\right]+\left[\begin{array}{l}
0 \\
-V_{b} \\
L_{2} \\
I_{m} \\
C_{d c} \\
0
\end{array}\right]
$$

According to Lyapunov stability theorem, a non-linear autonomous system is globally stable if satisfies the following conditions [18]:

$$
\left\{\begin{array}{l}
V(0)=0 \\
\alpha(\|\boldsymbol{x}\|)<V(\boldsymbol{x})<\beta(\|\boldsymbol{x}\|) \\
\dot{V}(\boldsymbol{x})<-\gamma(\|\boldsymbol{x}\|) \\
\lim V \rightarrow \infty \\
\|\boldsymbol{x}\| \rightarrow \infty
\end{array}\right.
$$

where Lyapunov function $V: \mathbb{R}^{n} \rightarrow \mathbb{R} \geq 0$ for $\dot{\boldsymbol{x}}=\boldsymbol{f}(\boldsymbol{x})$ is a continuously differentiable function such that there exist $\alpha$, $\beta$ belong to class $K_{\infty}$, a continuous positive definite function $\gamma: \mathbb{R}^{n} \rightarrow \mathbb{R} \geq 0$ for $\boldsymbol{x} \in \mathbb{R}^{n}$ [19]. State variables of the system must be defined as a form of their errors:

$$
\left[\begin{array}{l}
x_{1} \\
x_{2} \\
x_{3} \\
x_{4}
\end{array}\right]=\left[\begin{array}{l}
I_{L_{1}}-I_{L_{1}}^{*} \\
I_{L_{2}}-I_{L_{2}}^{*} \\
V_{d c}-V_{d c}^{*} \\
V_{u c}-V_{u c}^{*}
\end{array}\right]
$$

where $x_{1}$ to $x_{4}$ are the errors of state variables; superscript * represents the reference values of corresponding variables. Matrix $\dot{X}$ is introduced as:

$$
\dot{\boldsymbol{X}}=\left[\begin{array}{c}
\dot{x}_{1} \\
\dot{x}_{2} \\
\dot{x}_{3} \\
\dot{x}_{4}
\end{array}\right]=\left[\begin{array}{llll}
\frac{-R_{u c}}{L_{1}} & \frac{d_{3} R_{u c}}{L_{1}} & \frac{d_{12}}{L_{1}} & \frac{-1}{L_{1}} \\
0 & 0 & 0 & \frac{d_{3}}{L_{2}} \\
\frac{-d_{12}}{C_{d c}} & 0 & 0 & 0 \\
\frac{1}{C_{u c}} & \frac{-d_{3}}{C_{u c}} & 0 & 0
\end{array}\right]\left[\begin{array}{l}
x_{1} \\
x_{2} \\
x_{3} \\
x_{4}
\end{array}\right]+\boldsymbol{B}
$$

where $\boldsymbol{B}$ is the input matrix and includes system inputs and constant values of state matrix, calculated as:

$$
\begin{aligned}
\boldsymbol{B}= & {\left[\begin{array}{llll}
-\frac{R_{u c}}{L_{1}} & \frac{d_{3} R_{u c}}{L_{1}} & \frac{d_{12}}{L_{1}} & -\frac{1}{L_{1}} \\
0 & 0 & 0 & \frac{d_{3}}{L_{2}} \\
-\frac{d_{12}}{C_{d c}} & 0 & 0 & 0 \\
\frac{1}{C_{u c}}-\frac{d_{3}}{C_{u c}} & 0 & 0
\end{array}\right]\left[\begin{array}{l}
I_{L_{1}}^{*} \\
I_{L_{2}}^{*} \\
V_{d c}^{*} \\
V_{u c}^{*}
\end{array}\right] } \\
& +\left[\begin{array}{l}
-\frac{\mathrm{d} I_{L_{1}}^{*}}{\mathrm{~d} t} \\
-\frac{V_{b}}{L_{2}}-\frac{\mathrm{d} I_{L_{2}}^{*}}{\mathrm{~d} t} \\
\frac{I_{m}}{C_{d c}}-\frac{\mathrm{d} V_{d c}^{*}}{\mathrm{~d} t} \\
-\frac{\mathrm{d} V_{u c}^{*}}{\mathrm{~d} t}
\end{array}\right]
\end{aligned}
$$

Lyapunov function can be introduced in any form, as a function of state variables and other parameters of the system. In this paper, in order to investigate the system stability, Lyapunov function is defined as:

$V=\frac{1}{2} L_{1} x_{1}^{2}+\frac{1}{2} L_{2} x_{2}^{2}+\frac{1}{2} C_{d c} x_{3}^{2}+\frac{1}{2} C_{u c} x_{4}^{2}$

The matrix form of (8) can be written as:

$V=\boldsymbol{X}^{\mathrm{T}} \boldsymbol{P} \boldsymbol{X}=\boldsymbol{X}^{\mathrm{T}}\left[\begin{array}{cccc}\frac{L_{1}}{2} & 0 & 0 & 0 \\ 0 & \frac{L_{2}}{2} & 0 & 0 \\ 0 & 0 & \frac{C_{d c}}{2} & 0 \\ 0 & 0 & 0 & \frac{C_{u c}}{2}\end{array}\right] \boldsymbol{X}$

According to the second condition of (4), $V$ must be between the smallest and the largest eigenvalues of $\boldsymbol{P}[20]$. Therefore $\alpha$ and $\beta$ in (4) are equal to the smallest and the largest eigenvalues of $\boldsymbol{P}$, respectively, namely $\lambda_{\min }$ and $\lambda_{\max }$ :

$\lambda_{\min }(\boldsymbol{P})\|\boldsymbol{x}\| \leq V \leq \lambda_{\max }(\boldsymbol{P})\|\boldsymbol{x}\|$

The purpose is to find a relation for $\dot{V}$ condition in (4). Merging (9) and (11) results in:

$\boldsymbol{X}^{\mathrm{T}} \boldsymbol{P} \boldsymbol{X} \leq \lambda_{\max }(\boldsymbol{P})\|\boldsymbol{x}\|$

Multiplying both sides of (11) with $-1 / \lambda_{\max }$ :

$-\|\boldsymbol{x}\| \leq-\frac{1}{\lambda_{\max }} \boldsymbol{X}^{\mathrm{T}} \boldsymbol{P} \boldsymbol{X}$

According to $\dot{V}<-\gamma\|\boldsymbol{x}\|$ in (4) and (12):

$\dot{V}<-\gamma\|\boldsymbol{x}\|<-\frac{\gamma}{\lambda_{\max }} \boldsymbol{X}^{\mathrm{T}} \boldsymbol{P} \boldsymbol{X}$

Therefore, it is certain that: 
$\dot{V}<-\frac{\gamma}{\lambda_{\max }} \boldsymbol{X}^{\mathrm{T}} \boldsymbol{P} \boldsymbol{X}$

A new parameter called $\boldsymbol{\delta}$ is defined as:

$$
\begin{aligned}
\boldsymbol{\delta} & =\left[\begin{array}{rrrr}
\delta_{1} & 0 & 0 & 0 \\
0 & \delta_{2} & 0 & 0 \\
0 & 0 & \delta_{3} & 0 \\
0 & 0 & 0 & \delta_{3}
\end{array}\right] \\
& =\frac{1}{2 \lambda_{\max }}\left[\begin{array}{rrrr}
L_{1} \gamma_{1} & 0 & 0 & 0 \\
0 & L_{2} \gamma_{2} & 0 & 0 \\
0 & 0 & C_{u c} \gamma_{3} & 0 \\
0 & 0 & 0 & C_{d c} \gamma_{4}
\end{array}\right]
\end{aligned}
$$

Therefore:

$$
\dot{V}<\boldsymbol{X}^{\mathrm{T}} \boldsymbol{\delta} \boldsymbol{X}
$$

Equation (8) satisfies the first, second and fourth conditions of (4). According to (16), the system is globally stable if the derivation of $V$ satisfies the following inequality:

$$
\begin{aligned}
\dot{V}= & L_{1} x_{1} \dot{x}_{1}+L_{2} x_{2} \dot{x}_{2}+C_{d c} x_{3} \dot{x}_{3}+C_{u c} x_{4} \dot{x}_{4} \\
& \leq \delta_{1} x_{1}^{2}+\delta_{2} x_{2}^{2}+\delta_{3} x_{3}^{2}+\delta_{4} x_{4}^{2}
\end{aligned}
$$

In this paper, references are time-invariant and constant. Therefore, the derivatives of reference values are zero and can be neglected in further calculations. Substituting (6) and (15) into (17), Lyapunov function's derivative form is calculated as (18) in which some terms (such as $-R_{u c} x_{1}^{2}$ ) are always negative and neglected and some are simplified. Furthermore, $d_{3}$ and $d_{12}$ must be calculated in a way that (18) stays negative and system remains globally stable, therefore:

$$
\begin{aligned}
\dot{V}= & L_{1} x_{1}\left(\frac{-R_{u c}}{L_{1}} x_{1}+\frac{d_{3} R_{u c}}{L_{1}} x_{2}+\frac{d_{12}}{L_{1}} x_{3}-\frac{1}{L_{1}} x_{4}\right. \\
& \left.-\frac{R_{u c}}{L_{1}} I_{L_{1}}^{*}+\frac{d_{3} R_{u c}}{L_{1}} I_{L_{2}}^{*}+\frac{d_{12}}{L_{1}} V_{d c}^{*}-\frac{1}{L_{1}} V_{u c}^{*}\right) \\
& +L_{2} x_{2}\left(\frac{d_{3}}{L_{2}} x_{4}+\frac{d_{3}}{L_{2}} V_{u c}^{*}-\frac{V_{b}}{L_{2}}\right) \\
& +C_{d c} x_{3}\left(\frac{-d_{12}}{C_{d c}} x_{1}-\frac{d_{12}}{C_{d c}} I_{L_{1}}^{*}+\frac{I_{m}}{C_{d c}}\right) \\
& +C_{u c} x_{4}\left(\frac{1}{C_{u c}} x_{1}-\frac{d_{3}}{C_{u c}} x_{2}+\frac{1}{C_{u c}} I_{L_{1}}^{*}-\frac{d_{3}}{C_{u c}} I_{L_{2}}^{*}\right) \\
& -\delta_{1} x_{1}^{2}-\delta_{2} x_{2}^{2}-\delta_{3} x_{3}^{2}-\delta_{4} x_{4}^{2} \leq 0 \\
d_{3}= & \frac{x_{1} V_{u c}^{*}+x_{2} V_{b}+\delta_{1} x_{2}^{2}+\delta_{2} x_{4}^{2}}{R_{u c} x_{1} x_{2}+R_{u c} x_{1} I_{L_{2}}^{*}+x_{2} V_{u c}^{*}-x_{4} I_{L_{2}}^{*}} \\
d_{12}= & \frac{R_{u c} x_{1} I_{L_{1}}^{*}-x_{4} I_{L_{1}}^{*}-x_{3} I_{m}+\delta_{4} x_{1}^{2}+\delta_{3} x_{3}^{2}}{x_{1} V_{d c}^{*}-x_{3} I_{L_{1}}^{*}}
\end{aligned}
$$

\subsection{Energy management algorithm}

As shown in Fig. 3, the switching between the modes is carried out according to SOC of battery, ultra-capacitor and DC link voltage, i.e., $S O C_{b}, S O C_{u c}$ and $V_{d c}$. The maximum and minimum values of $S O C_{u c}, S O C_{b}$ and $V_{d c}$ are chosen according to the systems' requirements. In this case, $S O C_{u c}, S O C_{b}$ are chosen as a value between 0 and $100 \%$, and $V_{d c \text {,max }}$ and $V_{d c \text {,min }}$ are voltage parameters based on operator's choice. The system has three operational modes that are not enabled together, and priority of these modes is based on the followings: (1) ultra-capacitor charging by DC link voltage when $V_{d c}>V_{d c, \max }, S O C_{u c}<S O C_{u c \text {, max }}$; (2) DC link capacitor charging by ultra-capacitor when $V_{d c}<V_{d c, \text { min }}, S O C_{u c}>S O C_{u c \text {,min }}$; (3) battery charging by ultra-capacitor when $V_{d c, \text { min }}<V_{d c}<V_{d c \text {, max }}, \quad S O C_{u c}$ $>S O C_{u c, \min }, S O C_{b}<S O C_{b, \max }$. And an auxiliary mode with following conditions: $V_{d c}>V_{d c, \max }, \quad S O C_{u c}>$ $S_{\text {SOC }}$ max.

Figure 4 shows the complete system diagram based on different sections, including controller, energy management system, IEM, inverter, and rectifier, where $u_{1}, u_{2}$ and $u_{3}$ are gating signal of $\mathrm{S} 1, \mathrm{~S} 2$ and $\mathrm{S} 3$, respectively.

\section{Simulation results}

Parameters of the system are shown in Table 1. Figure $5 \mathrm{a}$ shows the speed characteristics of IEM during a $16 \mathrm{~s}$ cycle. It must be noted that the acceleration and the deceleration rates of IEM should be within a permissible

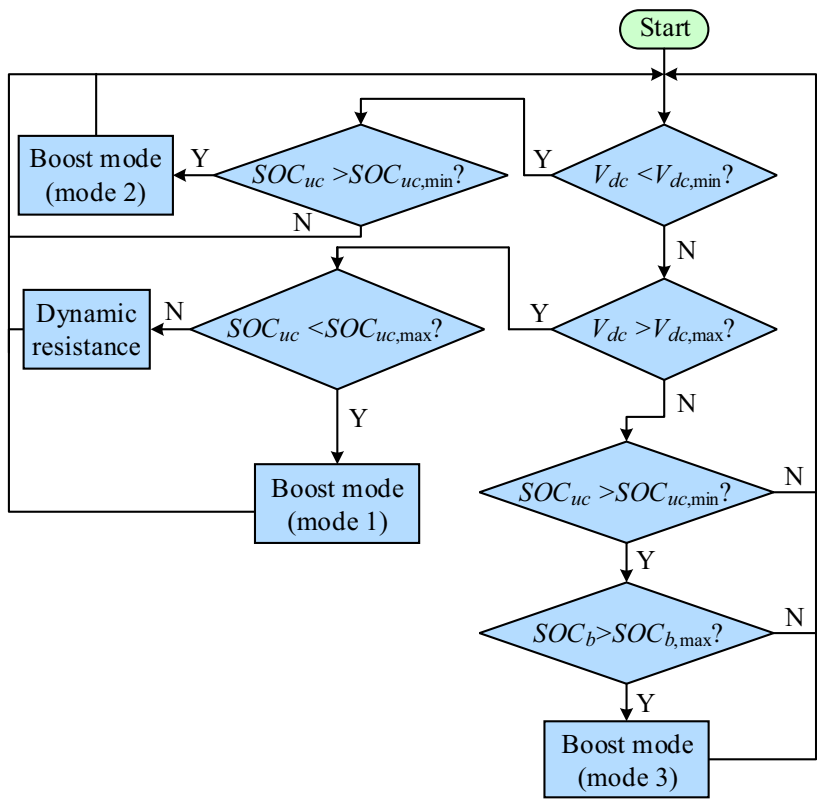

Fig. 3 Flowchart of energy management algorithm of proposed system 


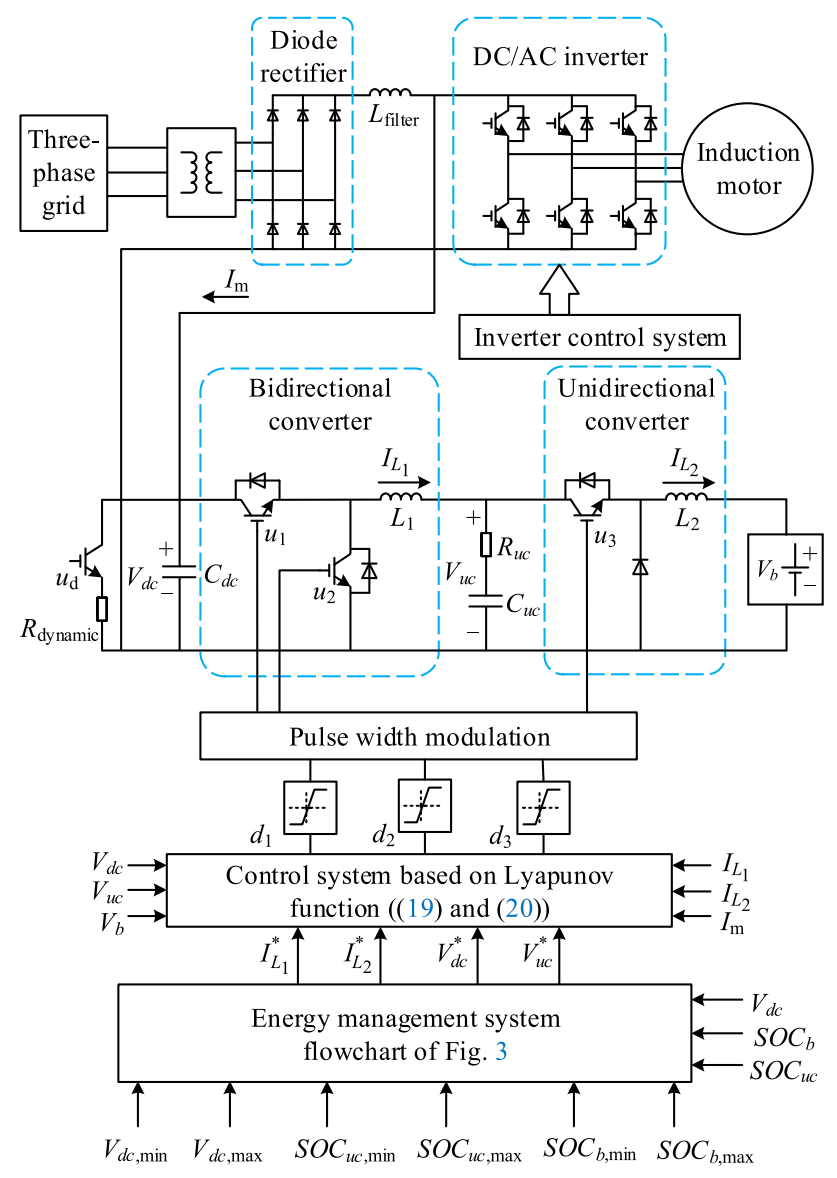

Fig. 4 Complete system circuit model

Table 1 Parameters of electrical machine, grid and proposed drive

\begin{tabular}{ll}
\hline Parameter & Value \\
\hline Nominal power & $37.3 \mathrm{~kW}$ \\
Nominal voltage and frequency & $460 \mathrm{~V}, 60 \mathrm{~Hz}$ \\
Grid voltage & $367 \mathrm{~V}$ \\
Grid inductor & $2 \mathrm{mH}$ \\
DC link capacitor & $1.6 \mathrm{mF}$ \\
Bidirectional converter inductor & $3.3 \mathrm{mH}$ \\
Unidirectional converter inductor & $33 \mathrm{mH}$ \\
Ultra-capacitor & $21.27 \mathrm{~F}$ \\
Series resistance & $0.1 \Omega$ \\
Battery voltage & $24 \mathrm{~V}$ \\
\hline
\end{tabular}

range (less than $1 \mathrm{~m} / \mathrm{s}^{2}$ ). As observed in the figure, the speed reaches $100 \mathrm{rad} / \mathrm{s}$ in $2 \mathrm{~s}$ and when braking, it decreases from $150 \mathrm{rad} / \mathrm{s}$ to $0 \mathrm{rad} / \mathrm{s}$ in $3 \mathrm{~s}$.

Figure $5 \mathrm{~b}$ shows torque curve during cycle. When the IEM accelerates, torque is positive and when the IEM brake, torque is negative. Figure $5 \mathrm{c}$ shows DC link voltage

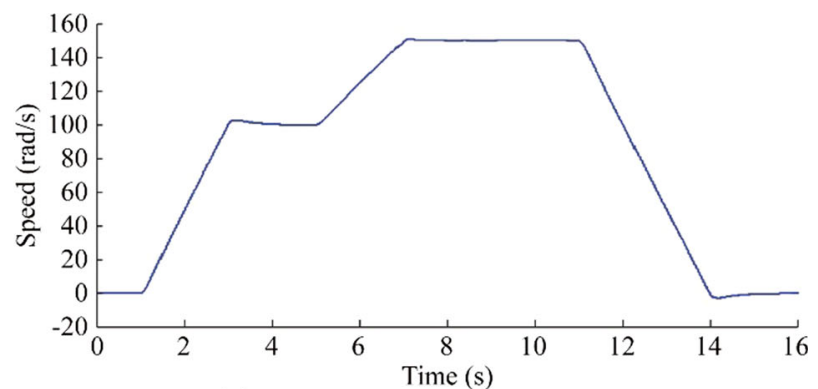

(a) IEM speed curve for 16-second period

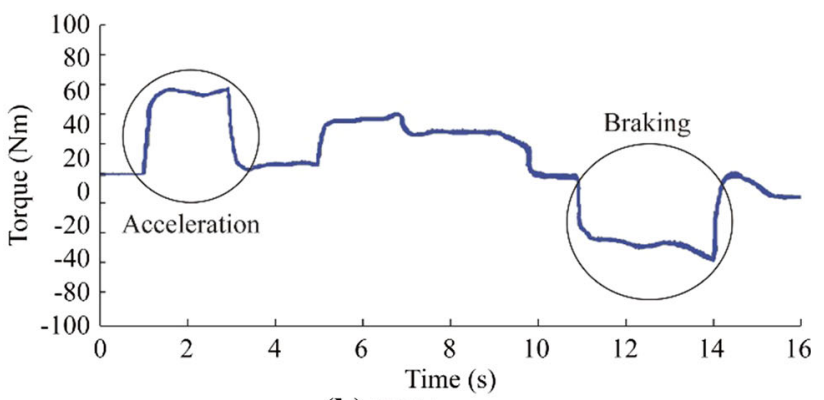

(b) IEM torque curve

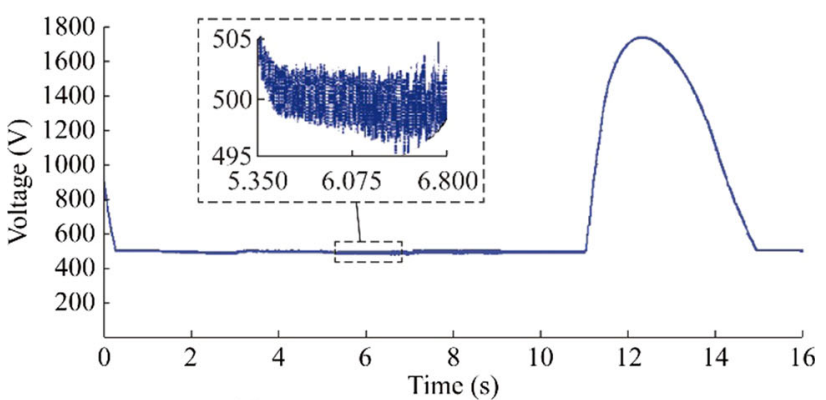

(c) DC link voltage due to IEM activity

Fig. 5 IEM speed curve for 16-second period, IEM torque curve and DC link voltage due to IEM activity

during this cycle. When the IEM accelerates at $5 \mathrm{~s}, V_{d c}$ drops and when IEM brakes at $11 \mathrm{~s}, V_{d c}$ increases.

The main idea of the proposed control system is to store regenerative energy in ultra-capacitor and battery. Besides that, whenever $V_{d c}$ drops down, ultra-capacitor will supply DC link capacitor with its charged energy. The proposed system must work accurately based on flowchart shown in Fig. 3 and track the reference values of state variables, $I_{L_{1}}^{*}=1 \mathrm{~A}$ (buck), $I_{L_{1}}^{*}=20 \mathrm{~A}$ (boost), $I_{L_{2}}^{*}=2 \mathrm{~A}, \quad V_{d c}^{*}=$ $500 \mathrm{~V}$ and $V_{u c}^{*}=30 \mathrm{~V}$.

Figure 6 shows DC link voltages before and after applying the proposed system with control parameters $\delta_{1}=-60, \delta_{2}=-0.2, \delta_{3}=-5, \delta_{4}=-0.1$. After applying the proposed system, the extra energy resulted by braking process must be stored in ultra-capacitor. Also, DC link voltage drop resulted by acceleration process is compensated by energy stored in ultra-capacitor. As seen, at $11 \mathrm{~s}$, $V_{d c}$ rises during the braking of IEM. Before applying the 


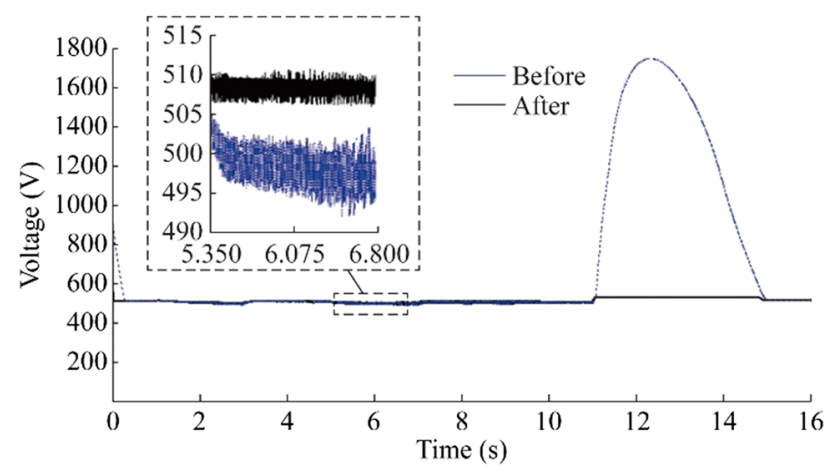

Fig. 6 Comparison of DC link voltage before and after applying proposed system

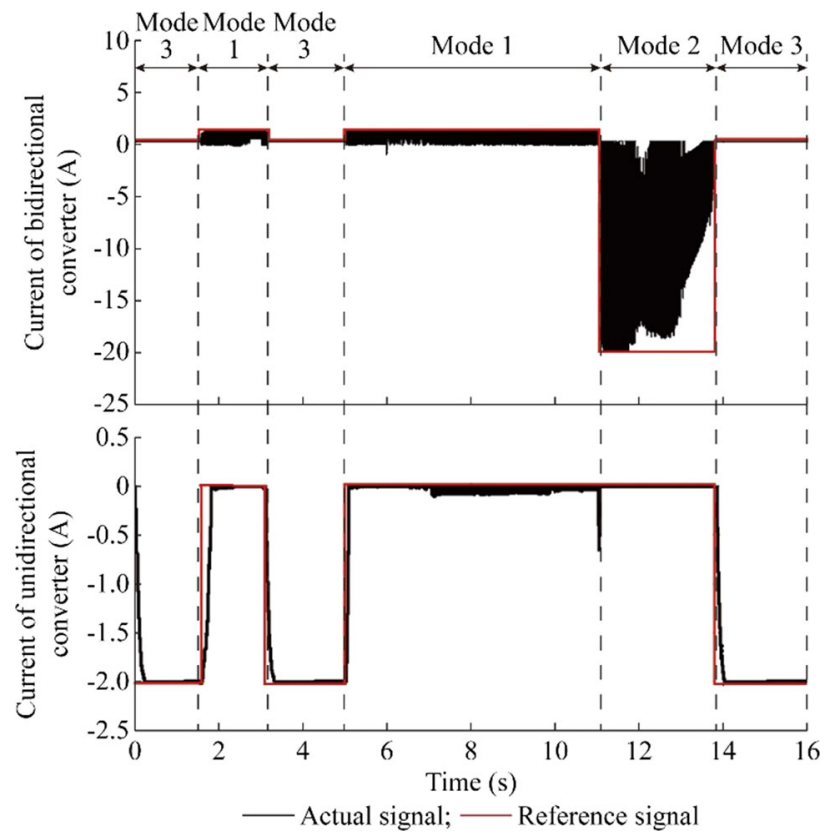

Fig. 7 Currents of bidirectional converter and unidirectional converter

proposed system, in this moment $V_{d c}$ reaches $1800 \mathrm{~V}$ but after applying the proposed system, $V_{d c}$ is limited near to $500 \mathrm{~V}$. Energy management system decides whenever $V_{d c}$ is higher than $V_{d c \text {, max }}$ and $S O C_{u c}$ is lower than $S O C_{u c \text {, max }}$, and then the bidirectional converter operated in buck mode. Other modes are basically applicable according to the requirements of the system and the energy management system designed in the previous section. As shown in Fig. 6, in the 5-7 s, DC link voltage drops, ultra-capacitor charges the DC link capacitor.

The energy management system works according to defined modes of Fig. 3. As seen in Fig. 7, there is not any interference between three modes, and it can be concluded that EMS works properly and in accordance with system's needs. Reference values for modes 1, 2 and 3 are $1 \mathrm{~A}, 20 \mathrm{~A}$ and $2 \mathrm{~A}$, respectively. As seen in the Fig. 7a ultra-capacitor

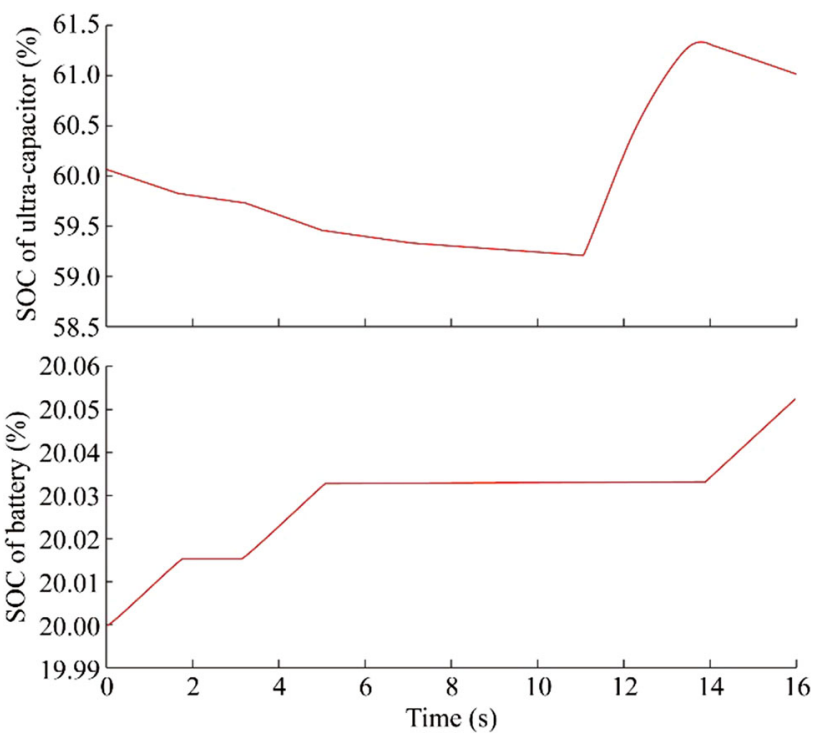

Fig. 8 SOC of ultra-capacitor and SOC of battery

charging and discharging currents are $20 \mathrm{~A}$ and $1 \mathrm{~A}$, respectively, the same as reference values. Also, Fig. 7b shows battery charging current which is exactly $2 \mathrm{~A}$, as seen the reference value is effectively followed.

Figure 8 shows the SOC of ultra-capacitor and battery during the 16-second period. It can be observed that ultracapacitor charges DC link capacitor or battery, or is charged by $V_{d c}$, and therefore the SOC of ultra-capacitor is always alternating (decreasing or increasing). However, since battery is operating only when unidirectional converter is activated, its SOC is sometime constant and the other times increasing.

As seen in Fig. 1b, there is an auxiliary load that uses the energy stored in battery. Due to different reference currents of ultra-capacitors in modes 1 and 2, whenever the system operates in mode $2, S O C_{u c}$ rises sharply and whenever system works in mode $1, S O C_{u c}$ falls slowly. On the other hand, the incline of $S_{O} C_{b}$ is always constant because reference current of battery is always $2 \mathrm{~A}$ and doesn't change. Because of very high amount of regenerative energy that is generated while braking, whenever the IEM enters braking mode, the SOC of ultra-capacitor sees the biggest changes. It is also observed that all of ultracapacitor energy that is consumed by DC link capacitor and battery before $11 \mathrm{~s}$, is compensated after $11 \mathrm{~s}$ due to braking process.

Figure 9 shows voltages during the 16 -second period. It can be seen that whenever $V_{d c}$ increases (and $S O C_{u c}$ is lower than $S O C_{u c, \max }$ ), bidirectional converter works in buck mode, ultra-capacitor gets charged and battery voltage remains constant. Whenever $V_{d c}$ decreases, ultra-capacitor voltage decreases to charge the DC link capacitor and compensate voltage drop in DC link. In mode 3, 


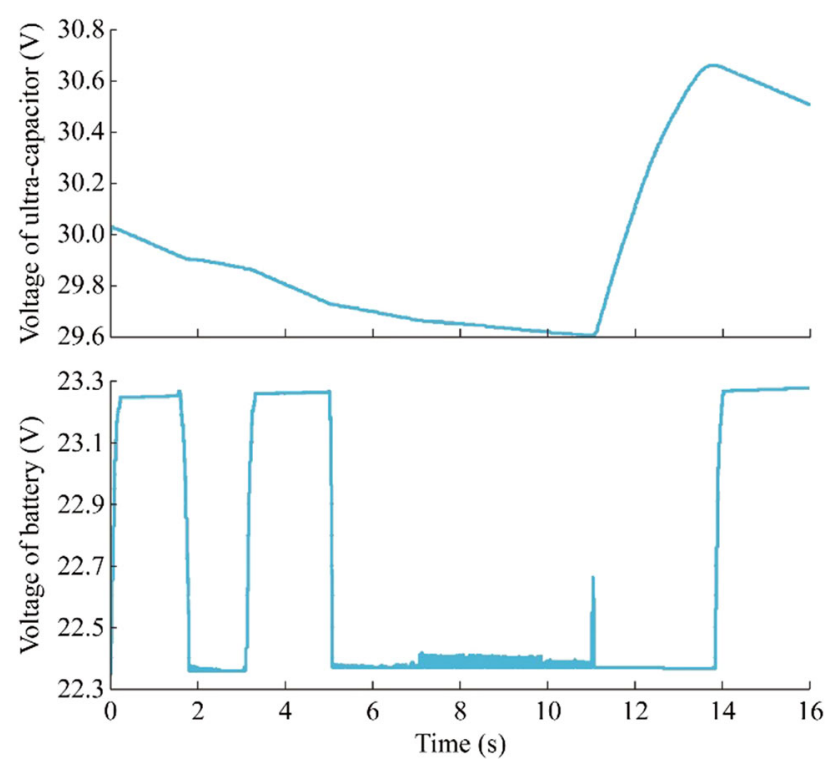

Fig. 9 Ultra-capacitor voltage and battery voltage
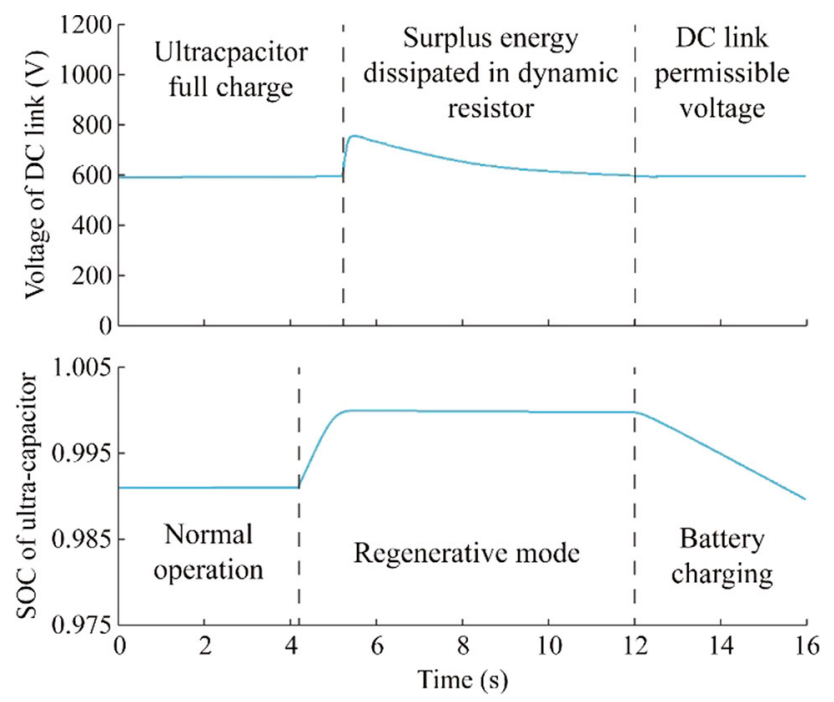

Fig. 10 DC link voltage and SOC of ultra-capacitor

whenever DC link voltage is in admissible range and $S O C_{u c}$ is higher that $S O C_{u c \text {,max }}$, battery gets charged by the energy stored in ultra-capacitor. Whenever battery is being charged, a $0.9 \mathrm{~V}$ growth in battery voltage can be seen.

As seen in Fig. 10, the surplus energy must be consumed and dissipated in dynamic resistor to prevent any damage to DC link equipment. As seen in the figure, when the IEM starts to regenerate energy, ultra-capacitor gets charged and as soon as it reaches its maximum capacity, the surplus energy in DC link is consumed in dynamic resistor and dissipated as heat. When DC link enters its permissible range again, ultra-capacitor starts charging the battery with its stored energy. As mentioned before, only one mode can be enabled at any moment, therefore ultra- capacitor charging the battery and dynamic resistor modes can't be enabled together.

\section{Conclusion}

In this paper, a topology for saving regenerative braking energy in ultra-capacitor and battery was proposed. The proposed circuit is also able to compensate DC link voltage drop, while IEM needs to accelerate. The topology is based on cascade structure of DC/DC converters. The controller is designed based on Lyapunov stability theorem that guarantees system's global stability. Simulation results validate that the proposed system works properly and all reference values are accurately tracked. It is also shown that energy management algorithm works in coordination with the controller. The proposed system can be implemented in all devices and facilities equipped with induction machines in order to store additional energy and consequently reducing the total costs.

Open Access This article is distributed under the terms of the Creative Commons Attribution 4.0 International License (http:// creativecommons.org/licenses/by/4.0/), which permits unrestricted use, distribution, and reproduction in any medium, provided you give appropriate credit to the original author(s) and the source, provide a link to the Creative Commons license, and indicate if changes were made.

\section{References}

[1] Erdogan N, Erden F, Kisacikoglu M (2018) A fast and efficient coordinated vehicle-to-grid discharging control scheme for peak shaving in power distribution system. J Mod Power Syst Clean Energy 6(5):555-566

[2] Xue Y, Cai B, James G et al (2014) Primary energy congestion of power systems. J Mod Power Syst Clean Energy 2(1):39-49

[3] González-Gil A, Palacin R, Batty P (2015) Optimal energy management of urban rail systems: key performance indicators. Energy Convers Manag 90:282-291

[4] Korayem MH, Imanian A, Tourajizadeh H (2013) A novel method for simultaneous control of speed and torque of the motors of a cable suspended robot for tracking procedure. Sci Iran 20(5):1550-1565

[5] Yang Z, Yang Z, Xia H et al (2018) Brake voltage following control of supercapacitor-based energy storage systems in metro considering train operation state. IEEE Trans Ind Electron 65(8):6751-6761

[6] Zhu F, Yang Z, Xia H (2018) Hierarchical control and full-range dynamic performance optimization of the supercapacitor energy storage system in urban railway. IEEE Trans Ind Electron 65(8):6646-6656

[7] Aguado JA, Racero AJS, Torre SDL (2018) Optimal operation of electric railways with renewable energy and electric storage systems. IEEE Trans Smart Grid 9(2):993-1001

[8] Sabzi S, Asadi M, Moghbelli H (2017) Review, analysis and simulation of different structures for hybrid electrical energy storages. Energy Equip Syst 5(2):115-129 
[9] Moghbelli H, Sabzi S (2015) Analysis and simulation of hybrid electric energy storage (HEES) systems for high power applications. In: Proceedings of ASEE annual conference and exposition, Seattle, USA, 26-28 June 2015, pp 1-13

[10] Khalilnejad A, Sundararajan A, Sarwat AI (2018) Optimal design of hybrid wind/photovoltaic electrolyzer for maximum hydrogen production using imperialist competitive algorithm. J Mod Power Syst Clean Energy 6(1):40-49

[11] Rufer A, Barrade P, Hotellier D (2004) Power-electronic interface for a supercapacitor-based energy-storage substation in DC-transportation networks. EPE J 14(4):43-49

[12] Lhomme W, Delarue P, Barrade P (2005) Design and control of a supercapacitor storage system for traction applications. In: Proceedings of 14th IAS annual meeting, Hong Kong, China, 2-6 October 2005, pp 2013-2020

[13] Zhang J, Lai J-S, Kim R et al (2007) High-power density design of a soft-switching high-power bidirectional DC-DC Converter. IEEE Trans Power Electron 22(4):1145-1153

[14] Grbović PJ, Delarue P, Moigne PL et al (2010) A bidirectional three-level DC-DC converter for the ultracapacitor applications. IEEE Trans Ind Electron 57(10):3415-3430

[15] Sabzi S, Asadi M, Moghbelli H (2016) Design and analysis of Lyapunov function based controller for DC-DC boost converter. Indian J Sci Technol 9(48):1-6

[16] Asadi M, Jalilian A (2012) Three-level NPC inverter control system of hybrid active power filter by modulation ratios of switching functions. In: Proceedings of 17th conference on electrical power distribution networks (EPDC), Tehran, Iran, 2-3 May 2012, pp 1-8

[17] Erickson RW, Maksimovic D (1997) Fundamentals of power electronics. Springer, Heidelberg

[18] Fadil HE, Giri F, Guerrero JM et al (2014) Modeling and nonlinear control of a fuel cell/supercapacitor hybrid energy storage system for electric vehicles. IEEE Trans Veh Technol 63(7):3011-3018
[19] Kellett CM (2014) A compendium of comparison function results. Math Control Signals Syst 26(3):339-374

[20] Cheng G, Luo X, Li L (2012) The bounds of the smallest and largest eigenvalues for rank-one modification of the Hermitian eigenvalue problem. Appl Math Lett 25(9):1191-1196

Shahab SABZI received his B.S. and M.S. degrees in 2013 and 2016 at Kermanshah Higher Education Institute and Arak University of Technology, respectively. From 2014 to 2015, he worked with Esfahan Metro Organization as a researcher. His research interests are power electronic, DC/DC converter modeling and control and Renewable energy resources.

Mehdi ASADI was awarded B.Sc., M.Sc., and Ph.D. degrees in electrical engineering from Iran University of Science and Technology (IUST), Tehran, Iran in 2002, 2004, and 2013, respectively. He is currently working with Arak University of Technology. His research interests include power electronic, power quality, and electrical machine drives.

Hasan MOGHBELLI received the B.S. degree from IUST, Tehran, Iran, in 1973, the M.S. degree from Oklahoma State University, Stillwater, in 1978, and the Ph.D. degree from the University of Missouri-Columbia (UMC), Columbia, in 1989, all in electrical engineering. He is a member of the American Society of Mechanical Engineers (ASME) and the Society of Automotive Engineers (SAE). $\mathrm{He}$ is currently an assistant professor at Arak University of Technology. He is also a visiting assistant professor in the Department of Science and Mathematics, Texas A\&M University at Qatar, Doha, Qatar. He has directed several projects in the area of electric drives, power systems, electric vehicles, hybrid electric and fuel cell vehicles, and railway electrification. His current research interests include electric drives, power electronics, and design of electric and hybrid electric vehicle. 